\title{
Notes on the Ecology and Morphology of the Cuban Khaki Trope, Tropidophis hendersoni Hedges and Garrido (Squamata: Tropidophiidae), with a New Locality Record
}

\author{
Luis M. Díaz ${ }^{1}$, Antonio Cádiz ${ }^{2}$, Sandy Villar ${ }^{3}$ and Feliberto Bermudez 4 \\ ${ }^{1}$ Museo Nacional de Historia Natural de Cuba. Habana Vieja, Cuba (luisfromcuba@yahoo.es) \\ ${ }^{2}$ Facultad de Biología, Universidad de La Habana, Ciudad de La Habana, Cuba (cadiz@fbio.uh.cu) \\ ${ }^{3}$ Museo de Historia Natural Joaquín de la Vara, Gibara, Holguín, Cuba \\ ${ }^{4}$ Local naturalist, Gibara, Holguín, Cuba \\ Photographs by the senior author except where indicated.
}

$\mathrm{H}^{\mathrm{s}}$ edges and Garrido (2002) described the Cuban Khaki Trope (Tropidophis hendersoni) from a single female specimen collected in 1945 in Guardalavaca, Holguín Province, and deposited in the Museum of Comparative Zoology at Harvard University (MZC 47896). This specimen was for a long time identified as T. haetianus (Schwartz and Henderson 1991, Tolson and Henderson 1993). The species was listed as Critically Endangered by Rodríguez Schettino and Garrido (2012) in the Red Book of Cuban Vertebrates based on available information, but no data on morphological variation, coloration in life, ecology, or new distributional records have come to light since the original description. The following note is a contribution to these topics based on additional specimens from a new locality. All specimens were deposited in the herpetological collection of Museo Nacional de Historia Natural de Cuba (MNHNCu).

On 14-15 August 2012 and 23-25 October 2013, we conducted two herpetological expeditions to Gibara, Holguín
Province, and found six specimens of $T$. hendersoni (Table 1, Figs. 1-4). This new locality (Fig. 2) is about $68 \mathrm{~km} \mathrm{NW}$ from Guardalavaca, and is in a sub-coastal karstic plateau with abundant caves. The original habitat surrounding the caves is semideciduous forest on limestone of marine origin. Many of these caves have sinkholes that allow sunshine and rain to enter, conditions conducive to the development of shrubs and vines in some chambers. The cave floor is red soil with rock mounds under sinkholes. Human impact is evident in this area (rubbish dumping, cattle farming, and military use of caves). The highly invasive Sicklebush (Dichrostachys cinerea) forms dense thickets, displacing original vegetation.

During the first expedition we found a single female (MNHNCu 4711) at Cueva de Los Panaderos $\left(21^{\circ} 06^{\prime} 21.1^{\prime \prime} \mathrm{N}\right.$; $\left.76^{\circ} 08^{\prime} 17.6^{\prime \prime} \mathrm{W}\right),-20 \mathrm{~m}$ asl, in the town of Gibara. This female was active at night $(2200 \mathrm{~h})$ on the floor of one of the cave galleries, about $100 \mathrm{~m}$ from the entrance. On the night of 24 October 2014, after a brief but heavy rain, we found two

Table 1. Main measurements of six specimens of Tropidophis hendersoni from Gibara, Holguín Province, Cuba.

\begin{tabular}{lccccccc} 
MNHNCu & Sex & $\begin{array}{c}\text { SVL } \\
(\mathbf{m m})\end{array}$ & $\begin{array}{c}\text { TL } \\
(\mathbf{m m})\end{array}$ & $\begin{array}{c}\text { Ventral } \\
\text { scales }\end{array}$ & $\begin{array}{c}\text { Subcaudal } \\
\text { scales }\end{array}$ & $\begin{array}{c}\text { Middorsal } \\
\text { enlarged spots } \\
\text { (right/left rows) }\end{array}$ & $\begin{array}{c}\text { Dorsal } \\
\text { scale row } \\
\text { formula }\end{array}$ \\
\hline 4711 & + & 322 & 37.2 & 202 & 33 & $53 / 53$ & $25-27-19$ \\
\hline 5055 & $\sigma^{\pi}$ & 331 & 43.2 & 202 & 34 & $55 / 55$ & $23-25-19$ \\
\hline 5056 & $\sigma^{\pi}$ & 332 & 42.5 & 195 & 30 & $50 / 48$ & $27-27-20$ \\
\hline 5057 & $\sigma^{\pi}$ & 267 & 31.0 & 203 & 32 & $57 / 57$ & $25-27-19$ \\
\hline 5058 & + & 327 & 37.7 & 204 & 31 & $50 / 50$ & $27-27-20$ \\
\hline 5059 & + & 305 & 34.7 & 198 & 31 & $50 / 57$ & $25-27-19$ \\
\hline
\end{tabular}



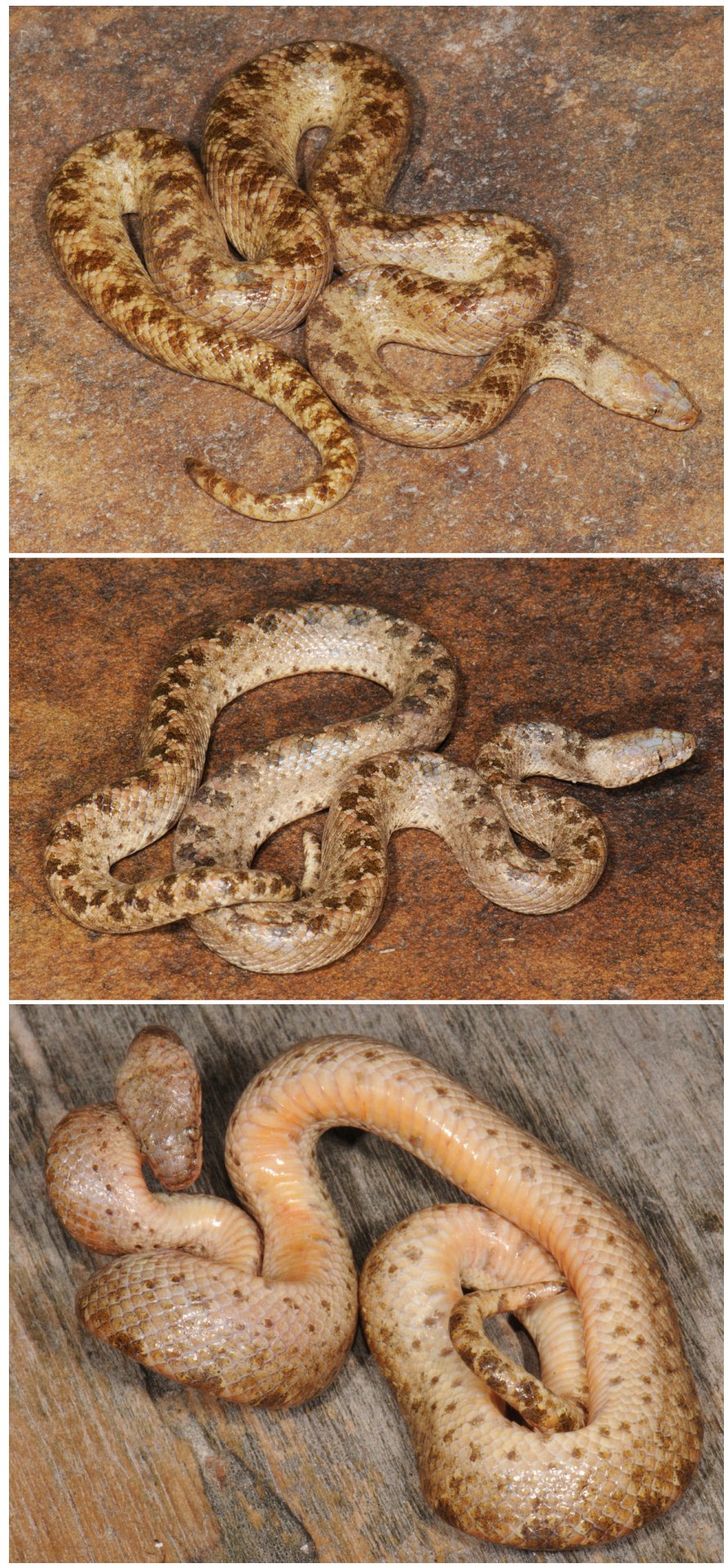

Fig. 1. Adult male Cuban Khaki Trope (Tropidophis hendersoni; $\mathrm{MNHNCu}$ 5056; top) and subadult male (MNHNCu 5057; middle and bottom).

additional individuals in Cueva de Los Panaderos (MNHNCu 5056-57) and three others (MNHNCu 5055, 5058, 5059) in Cueva del Santo $\left(21^{\circ} 06^{\prime} 17.7^{\prime \prime} \mathrm{N}\right.$; 7608'14.4”W), between 2100 and $2400 \mathrm{~h}$. The latter is, in fact, a different entrance into the same cave system located $150 \mathrm{~m}$ from Cueva de Los Panaderos. The three individuals in Cueva del Santo were col- lected in an area of fewer than $50 \mathrm{~m}^{2}$ that is associated with a sinkhole containing some vegetation, leaf litter, and rocks. Temperature was $28{ }^{\circ} \mathrm{C}$ and relative humidity $85 \%$. One snake was coiled in front of a decapitated fruit bat (Artibeus jamaicensis) lying on the ground and covered by flies. Frogs (Eleutherodactylus tonyi and E. cf. thomasi) were active nearby. We suspect that the snake was lying in wait for the frogs to approach in search of insects. Another individual was partially hidden within a hole in a rock, and retreated into the hole when disturbed by our headlamps. A male (MNHNCu 5055) was observed (Fig. 3) eating an adult frog Eleutherodactylus cf. thomasi. When discovered, more than half of the frog's body (head, forelimbs, and part of the trunk) had been swallowed by the snake, and ingestion was completed in less than 10 min. This individual was preserved $15 \mathrm{~h}$ later. The frog was recovered and measured $-38.5 \mathrm{~mm} \mathrm{SVL}$ and $96.4 \mathrm{~mm}$ from the tip of the snout to the fourth toe disk of the extended hindlimb; prey total length comprised $29 \%$ of snake SVL; measurements are approximate since the frog's head was in an advanced stage of digestion, but the rest of body was almost intact (Fig. 4). The other snakes were found crossing the cave floor. We found no individuals outside the cave system, and the probable association of this snake to this habitat might be explained by the abundance of frogs in the cave.

Other reptiles collected in the general area were Arrhyton taeniatum, Arrhyton sp., Tropidophis melanurus, T. wrighti, Sphaerodactylus nigropunctatus ssp., Tarentola americana, Anolis allisoni, $A$. angusticeps, $A$. centralis, A. jubar gibarensis, A. lucius, $A$. porcatus, and $A$. sagrei. Amphibians were represented by the previously mentioned two species of Eleutherodactylus and E. atkinsi, E. feichtingeri, E. ronaldi (new locality record), Osteopilus septentrionalis, and Peltophryne peltacephala. The Gracile Banded Trope (Tropidophis wrighti) was frequently found active in vegetation (as many as 20 individuals were seen in a few hours in just one night), foraging on thin branches at heights of $0.5-5 \mathrm{~m}$ above the ground, in sharp contrast with the more terrestrial habits of $T$. hendersoni. Sleeping anoles are known prey of $T$. wrighti, and arboreal foraging of this species might reduce competition with the more terrestrial species. At Cueva de Los Panaderos, we found a small juvenile T. melanurus, another terrestrial species and the largest known member of the genus. Cuba is the only place in the world with such a morphological and ecological radiation of Tropidophis (Hedges 2002).

Morphological data. - All individuals were quite similar, and pattern agrees with the original description, suggesting little variation of this character in adult individuals. Size for both sexes was longer than that reported for the holotype. Females were 305 and $327 \mathrm{~mm}$ SVL, respectively (vs. $280 \mathrm{~mm}$ in the holotype); adult males were 331 and $332 \mathrm{~mm} \mathrm{SVL}$ and one subadult male (MNHNCu 5057) was $267 \mathrm{~mm}$ SVL. Adult males had well developed pelvic spurs and slightly longer tails 

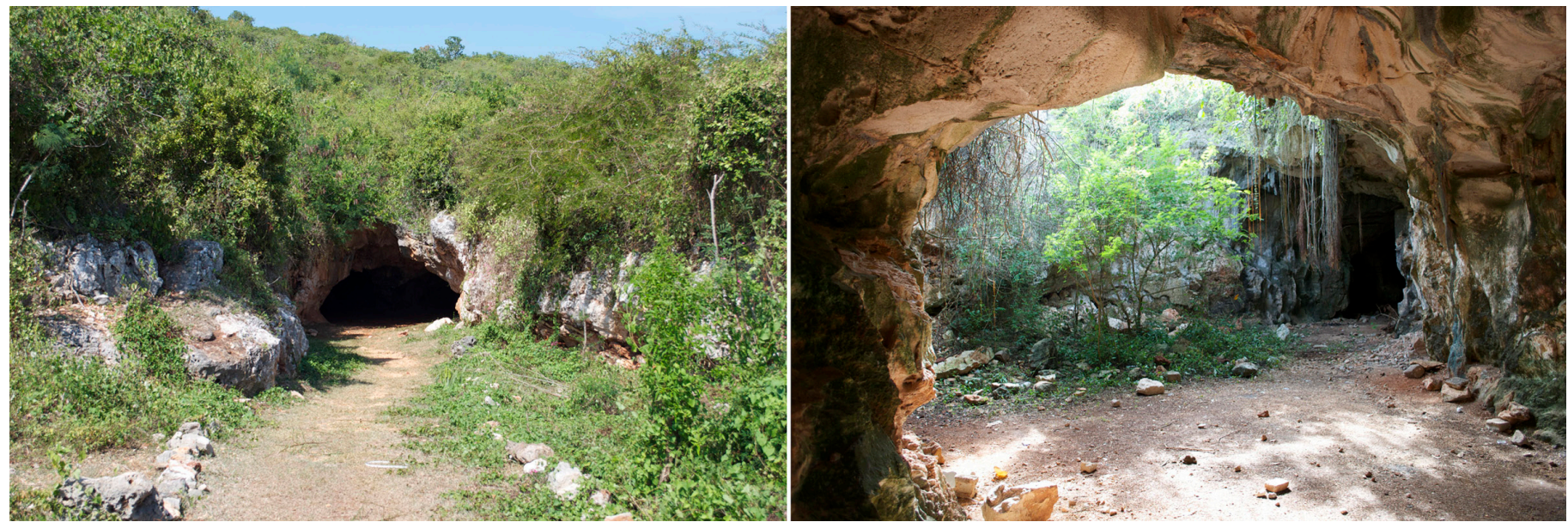

Fig. 2. Habitat of the Cuban Khaki Trope (Tropidophis hendersoni) in Gibara, Holguín Province, Cuba.Entrance of Cueva de Los Panaderos (left) and an area under a sinkhole with vegetation, leaf litter, and rocks at Cueva del Santo (right). Photographs by Antonio Cádiz.

than females (tail length $42.5-43.2 \mathrm{~mm}$ in males; vs. 34.7$37.7 \mathrm{~mm}$ in females). Spurs were dark brown, thick at the base, and with a nail-like projection in the distal half. Spurs retracted in small grooves (Fig. 5). In the young male, spurs were not developed but the spur-bearing grooves were evident. Hemipenes were bifurcated in one male (MNHNCu 5056).

Color in life was not available in the original description. The dorsum was tan in most specimens. The subadult male was more grayish than the others, and the middorsal spots were more conspicuously bordered by paler scales. The venter was paler than the dorsum, cream colored to slightly orange, immaculate or with sparse and widely spaced spots on the borders of some ventral scales. A pale, gray transverse occipital zone (a faded collar) was evident in all specimens, as mentioned in the original description. All individuals had a moderately evident brown postocular stripe extending obliquely

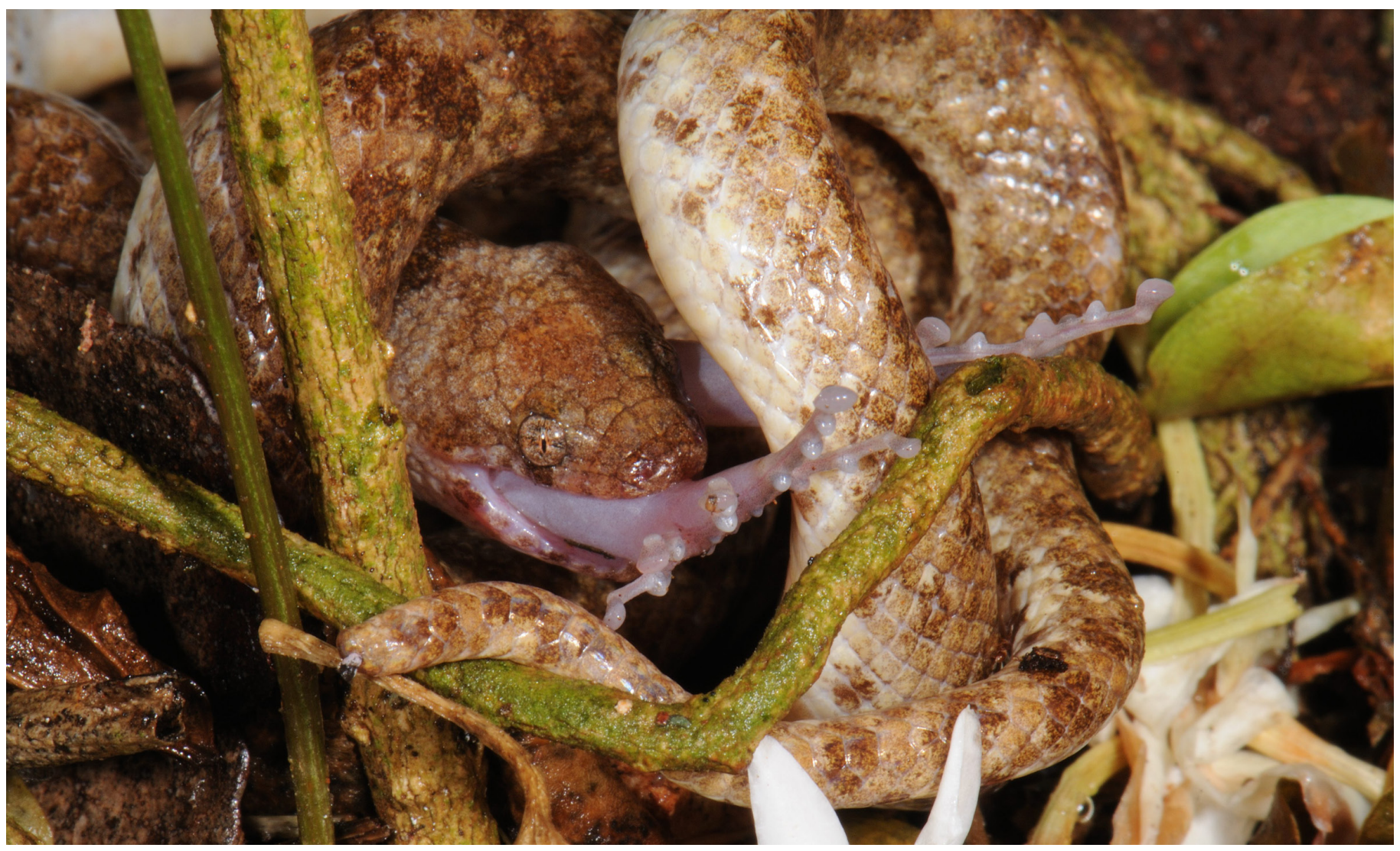

Fig. 3. Adult male Cuban Khaki Trope (Tropidophis hendersoni; MNHNCu 5055) ingesting a frog (Eleutherodactylus cf. thomasi) in Cueva del Santo, Gibara, Holguín Province. 


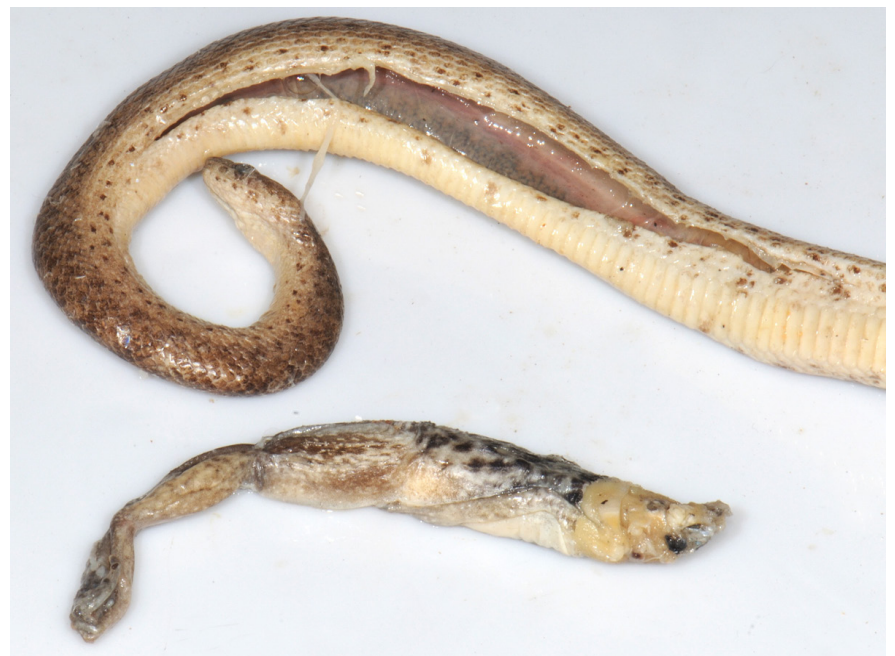

Fig. 4. Ingested frog (Eleutherodactylus cf. thomasi) recovered from the adult male Cuban Khaki Trope (Tropidophis hendersoni; MNHNCu 5055).

over the posterior supralabial scales but not beyond them. A subocular dark bar was most conspicuous and at least a few other bars were present on supralabial and infralabial scales, as mentioned by Hedges and Garrido (2002). The posterior half of the head in dorsal view was marked by a more-orless triangular or diamond-like dark figure. The nares were crossed by a barely evident brown band. The dorsal pattern consisted of two partially fused enlarged spots along the midline. Spots on the flanks were considerably smaller, irregularly aligned, and less contrasting than the enlarged middorsal spots. About 8-10 spots extended around midbody, which agrees with the condition described by Hedges and Garrido (2002). The tail tip was not distinctively differentiated, but had a slightly more accentuated yellowish cast in some individuals. Preoculars $1 / 1$; postoculars $3 / 3$; supralabials $9 / 9$ $(\mathrm{n}=3), 9 / 10(\mathrm{n}=1)$, and $10 / 9(\mathrm{n}=2)$; infralabials $11 / 10(\mathrm{n}=2)$, $11 / 11(n=4)$; ventral scales $195-204($ mean $=201)$; subcaudal scales 31-34 $($ mean $=32)$; dorsal scale row formula 23-25-19 $(\mathrm{n}=1$; also the female holotype condition), 25-27-19 $(\mathrm{n}=3)$, 27-27-20 ( $\mathrm{n}=2)$; number of middorsal enlarged spots (right/ left rows) from snout to vent 50/48, 50/50, 50/57, 53/53, $55 / 55$, and $57 / 57$ (51/51 in the female holotype). Parietal scales in contact in $\mathrm{MNHNCu} 5056$, partially separated in MNHNCu 5057-5059, or completely separated by one scale in $\mathrm{MNHNCu} 4711$ and 5055. The holotype has the first condition, but this is clearly a variable character. All specimens had weakly keeled dorsal scales at the level of the vent, as in the original description. Some of these measurements are summarized in Table 1.

\section{Acknowledgements}

We extend our thanks to Jonathan Losos for inviting the senior author to visit the Museum of Comparative Zoology (MCZ) at Harvard University in 2009, where José Rosado

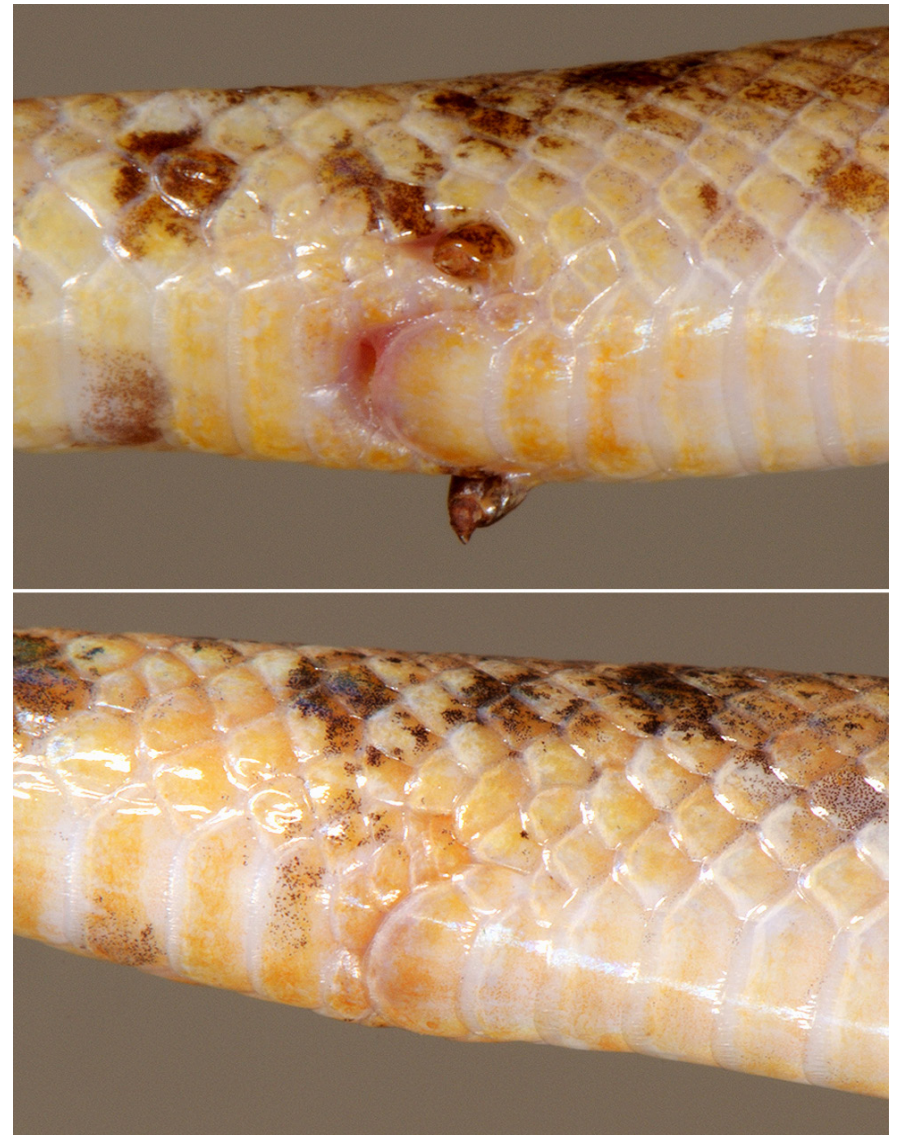

Fig. 5. Male Cuban Khaki Trope (Tropidophishendersoni; $\mathrm{MNHNCu}$ 5056; top) with pelvic spurs compared with the female ( $\mathrm{MNHNCu} 4711$ ) condition (bottom).

provided access to the holotype of Tropidophis hendersoni. Fieldwork was partially financed by the Systematic Research Fund of the Linnean Society of London and the Systematics Association (to LMD), the project "Ecology and Evolution of Cuban Anoles," Tohoku University of Japan (to AC), and the University of Würzburg, Germany. We are indebted to the Museo de Historia Natural Joaquín de la Vara and members of the Speleological Group of Gibara for logistical support. Robert Henderson kindly reviewed the first draft of this manuscript and provided useful comments.

\section{Literature Cited}

Hedges, S.B. 2002. Morphological variation and the definition of species in the snake genus Tropidophis (Serpentes, Tropidophiidae). Bulletin of the Natural History Museum of London (Zoology) 68:83-90.

Hedges, S.B. and O.H. Garrido. 2002. A new snake of the genus Tropidophis (Tropidophiidae) from eastern Cuba. Journal of Herpetology 36:157-161.

Rodríguez Schettino, L. and O.H. Garrido. 2012. Tropidophis hendersoni Hedges y Garrido, 2002. In: H.J. González Alonso, L. Rodríguez Schettino, A. Rodríguez, C.A. Mancina, and I. Ramos García (eds.), Libro Rojo de los Vertebrados de Cuba. Editorial Academia, La Habana.

Schwartz, A. and R.W. Henderson. 1991. Amphibians and Reptiles of the West Indies: Descriptions, Distributions, and Natural History. University of Florida Press, Gainesville.

Tolson, P.J. and R.W. Henderson. 1993. The Natural History of West Indian Boas. R \& A Publishing Limited, Taunton, Somerset, England. 